\title{
La pastoral de juventud y el Directorio para la catequesis 2020
}

Alfredo Delgado Gómez

\section{Resumen}

La publicación del nuevo Directorio para la Catequesis es una buena noticia para la pastoral de juventud, porque este directorio aborda de manera amplia el tema de cómo acercar el evangelio a los jóvenes. Este artículo quiere presentar las novedades del directorio relacionadas con la pastoral con los jóvenes. Asimismo este directorio, impulsado por el acento de la catequesis kerygmática, presenta varios desafíos que pueden resultar estimulantes para la pastoral de juventud, como la cultura digital, la catequesis familiar, la relación ciencia y fe, la ecología, la moral, etc. El Directorio se presenta como una brújula para la pastoral juvenil así como un buen test para cotejar nuestra realidad de acción pastoral.

\section{Palabras claves}

Pastoral juvenil, Catequesis, Evangelización, Cultura digital

\section{Introducción}

La publicación del Directorio para la Catequesis (DC, 2020) por el Pontificio Consejo para la Promoción de la Nueva Evangelización es una buena noticia para todos aquellos que estamos en la aventura de seguir anunciando a Jesús entre los jóvenes.

1 De hecho, "La Iglesia existe para evangelizar" EN 14. "Evangelizar es, ante todo, hacer presente y anunciar a Jesucristo" (DC 29). "La evangelización tiene como fin último la plenitud de la vida humana" (DC 30). "Evangelizar no significa ocupar un territorio, sino despertar procesos espirituales en la vida de las personas" (DC 43). "La evangelización, sostenida por el Paráclito, trata de hacer partícipe de este gran Misterio vivificante a todas las personas" (DC 427). 
Sin embargo surge el riesgo de que el DC pase desapercibido en el mundo de la pastoral juvenil y escolar, por no decir entre tantos sacerdotes y catequistas, cuando este documento es una especie de brújula para la labor evangelizadora de la Iglesia y por tanto el documento de referencia de la Iglesia para la Pastoral Juvenil (PJ). En este artículo se va a desarrollar una presentación de lo que aporta el DC a la $\mathrm{PJ}^{2}$, con el deseo de animar a la lectura y diálogo del DC por los agentes de la PJ y de la pastoral escolar.

\section{Breve presentación del DC}

El DC es un documento síntesis que intenta recoger de manera sistemática y organizada la enseñanza de la Iglesia Católica relacionada con la catequesis, entendida como una parte del proceso evangelizador ${ }^{3}$. Así lo señala el propio DC: "El criterio que guía la redacción de este Directorio para la catequesis es el deseo de profundizar en la tarea de la catequesis como dinámica de la evangelización" (DC 5). De hecho, es un documento que entiende la catequesis bajo la primacía de la evangelización. Por tanto, aquella persona que quiera tener una síntesis de lo que es la misión de la iglesia (evangelizar) no encuentra un documento más rico que el $\mathrm{DC}^{4}$.

El DC no es un documento normativo para todas las diócesis y circunstancias, sino que intenta dotar de un marco para que cada iglesia local pueda aterrizar en su situación particular estas intuiciones. No tiene pretensiones de "plenitud" y se reconoce como mejorable, porque por su naturaleza está destinado a las "iglesias particulares, de modo que se motiven y sean apoyadas para redactar sus propios Directorios". Por ello es conveniente

2 Bajo estas dos siglas acogemos todas las denominaciones y matices: Pastoral de Juventus, Pastoral con los jóvenes, etc.

3 "El criterio que guía la redacción de este Directorio para la catequesis es el deseo de profundizar en la tarea de la catequesis como dinámica de la evangelización" (DC 5).

4 DC 33-54. Sigue siendo muy conveniente leer DGC 14-59 dada que su presentación de la evangelización no ha sido mejorada. Se ha de recordar que mientras el concilio Vaticano II deseaba abordar el tema de la esencia y misión de la Iglesia (LG 1), la misión de la Iglesia quedó muy deslavazada en el concilio, y encontró su síntesis en la encíclica EN. 
recordar como lo hace el propio Directorio que: "Los obispos son los primeros destinatarios de este documento $0^{5}$.

El Directorio General para la Catequesis (DGC 1997), publicado en aquel entonces por la Congregación para el Clero, fue un documento pionero, tal vez una de las mejores elaboraciones del magisterio, por su capacidad de síntesis 6 . Fue un documento avanzado y sereno que presentaba el dinamismo de la evangelización de una manera orgánica, recogiendo las intuiciones del Concilio Vaticano II y sobre todo de Evangelii Nuntiandi (EN, 1975) y Cathechesis tradende (CT, 1979). Quiso este directorio situar en el dinamismo de la catequesis el Catecismo de la Iglesia Católica (CEC, 1992), surgido en los años anteriores8. El DGC impulsó de manera profunda el catecumenado como modelo de la catequesis y puso la catequesis de los adultos en el centro de la labor catequética de la Iglesia9. Muchas intuiciones de este DGC todavía no han sido desarrolladas en la mayoría de las diócesis.

El nuevo DC, publicado veinte años después del DGC, quiere seguir actualizando la presentación sistemática de la tarea evangelizadora y catequética de la Iglesia (DC 6), incluyendo las intuiciones novedosas que está aportando el magisterio del Papa Francisco y los

5 Cf. Fisichella en la Presentación.

6 Anteriormente ya se había publicado el Directorio catequístico general (1971), fruto del deseo del Vaticano II en CD 44 que pidió la redacción de un «Directorio sobre la formación catequética del pueblo cristiano».

7 El Sínodo de 1977 convocado por Pablo VI, estaba destinado a tratar la catequesis de niños y adolescentes. Todavía no se había tomado conciencia de la importancia de la catequesis de los adultos.

8 Hay que recordar que el Concilio Vaticano II rechazó la elaboración de un catecismo. G. Routhier, Benedetto Catechismo! Famiglie e parrocchie tra disagio e speranza, Torino 2008, 10. Según el propio CEC 24: "El Catecismo no es en sí mismo una propuesta de método catequístico, no da ninguna indicación al respecto, ni debe confundirse con el proceso de la catequesis, sobre el que siempre necesita de una mediación. orada, ayudando así a encontrarse con Cristo poco a poco. "La propuesta catequística, sin embargo, no sigue necesariamente el orden de las partes del Catecismo" (DC 190).

9 Habría que destacar asimismo la publicación del YouCat (2011) como una muy buena noticia para la Iglesia, dejando de lado su esquema de preguntas y respuestas, significó un soplo de aire fresco, especialmente en el contexto eclesial en el que surgió. 
recientes sínodos para la nueva evangelización ${ }^{10}$ y sobre los jóvenes ${ }^{11}$. Este directorio quiere incluir las intuiciones y apuestas pastorales del Papa Francisco tal y como aparecen en sus exhortaciones apostólicas Evangelii Gaudium (EG, 2013), Laudato Si (LS, 2015), Amoris Laetitia (AL, 2016) y Christus Vivit (ChV, 2019).

EL DC quiere adaptar asimismo la enseñanza de la Iglesia sobre la catequesis a los nuevos tiempos marcados por la globalización de la cultura (DC 319-328), el impacto de las redes sociales (DC 359-372; DC 45 y 47 los mass media), las nuevas configuraciones familiares (DC 233-235), etc. Todos estos aspectos son abordados por el DC de una manera positiva a la vez que propone una reflexión sobre posibles desafios y oportunidades de estas realidades emergentes.

Se pueden señalar varios acentos transversales en el DC. Primero, el protagonismo otorgado al primer anuncio o kerygma, impulsado por el Papa Francisco en Evangelii Gaudium ${ }^{12}$, que es de hecho el criterio que ha provocado la reflexión y la redacción de este Directorio. Se desarrolla y prioriza la catequesis kerygmática (DC 2; DC 57-58), una intuición que aglutina el primer anuncio, la evangelización y la catequesis. Y lanza un importante desafío para la Iglesia: "la Iglesia debe poder encarnar el kerygma para las exigencias de sus contemporáneos 13 ", de manera que "surjan anuncios creíbles, confesiones de fe vitales, nuevos himnos cristológicos para anunciar a cada persona la buena nueva" (DC 58). Creo que estos números del DC son un verdadero filón para la PJ.

Un segundo acento del DC, en continuidad con el DGC, es la estrecha unión entre evangelización y catequesis. De hecho la intención del DC "es profundizar en la tarea de la catequesis como dinámica

10 Sínodo sobre la nueva evangelización para la transmisión de la fe cristiana (2012).

11 Sínodo sobre los jóvenes, la fe y el discernimiento vocacional (2018).

12 Hemos redescubierto que también en la catequesis tiene un rol fundamental el primer anuncio o "kerygma", que debe ocupar el centro de la actividad evangelizadora y de todo intento de renovación eclesial. Es el primero en un sentido cualitativo, porque es el anuncio principal" (EG 164-165).

13 Evangelizar las culturas para inculturar el evangelio DC 43. Esta "ruptura entre Evangelio y cultura es sin duda el drama de nuestra época” (EN 20 y DC 103). 
de la evangelización” (DC 5). El proceso evangelizador ${ }^{14}$ está detallado en DC 31, un punto que hay que leer cuidosamente, donde se abordan diferentes temas centrales para la catequesis y la PJ, como es el tema de la conversión como punto clave para comenzar la catequesis, lo cual es un desafío para la PJ, que muchas veces va trenzando varios procesos simultáneos: la acción misionera, el primer anuncio, la catequesis e integración en la comunidad. Esta intuición de la PJ se ve ahora refrendada por el propio DC y su protagonismo de la catequesis kerygmática ${ }^{15}$. En este sentido se desarrolla la relación entre primer anuncio y catequesis (DC 66-68) un tema central en la PJ e impulsa a la Iglesia a estar con la gente allí donde ella está de hecho ${ }^{16}$. El DC lanza una constante llamada a evangelizar cada cultura y a estar presentes en medio del mundo ${ }^{17}$.

Se podrían señalar más acentos del documento en continuidad con el DGC como son: el protagonismo del Espíritu' ${ }^{18}$, la comprensión de la persona en camino (DC 3) y la reafirmación del papel de la comu-

14 Las etapas de este proceso evangelizador son: la acción misionera y el testimonio, conversión inicial, primer anuncio, Catequesis, integración en la comunidad (DC 33).

15 La catequesis, etapa privilegiada del proceso de evangelización, generalmente se dirige a las personas que ya han recibido el primer anuncio, en cuyo interior promueve los procesos de iniciación, crecimiento y maduración en la fe. Sin embargo, es cierto que, si bien la distinción conceptual entre pre-evangelización, primer anuncio, catequesis y formación permanente sigue siendo útil, en el contexto actual ya no es posible marcar esta diferencia. De hecho, por un lado, aquellos que hoy piden o ya han recibido la gracia de los sacramentos a menudo no tienen una experiencia explícita de fe. (DC 56).

16 Ver DC 49-50: En este sentido, la Iglesia será capaz de estar cerca de la gente de nuestro tiempo, siguiéndola allí donde están.

17 "Por ello, la comunidad eclesial anhela entrar en aquellos centros de la existencia, ámbitos antropológicos y areópagos modernos, donde se inician las tendencias culturales y se plasman nuevas mentalidades: la escuela, la investigación científica, los ambientes de trabajo; el área de los social media y de la comunicación; el ámbito de los compromisos por la paz, el desarrollo, la protección de lo creado, la defensa de los derechos de los más débiles; el mundo del tiempo libre, del turismo, del bienestar; el espacio de la literatura, de la música y de las diferentes expresiones artísticas. (DC 324).

18 El Espíritu Santo aparece por doquier en este documento. DC 23. "El catequista como un facilitador respetuoso de una experiencia de fe de la cual él no es el protagonista" (DC 148). "El verdadero protagonista de toda auténtica catequesis es el Espíritu" (DC 112). 
nidad como el lugar de maduración de la fe, el papel de la belleza como puerta a la trascendencia (DC 106-109). Se vuelve a subrayar con fuerza la necesidad de la formación de los catequistas (DC 130) y a las dimensiones del "ser, saber y saber hacer" del DGC (DGC 238) se añade ahora la dimensión del "saber ser con'19" (DC 136, 139-142).

Uno de los grandes aciertos de este DC es su descripción y conciencia de los signos de los tiempos actuales: "Entre esos signos se pueden reconocer: la centralidad del creyente y su experiencia de vida; el papel relevante de las relaciones personales y los afectos, la búsqueda de sentido de lo verdadero; el redescubrimiento de aquello que es bello y eleva el espíritu" (DC 5), así como su diagnóstico de los puntos cruciales en los que se encuentran los desafíos de la transmisión de la fe: el secularismo ${ }^{20}$ (DC 103), la complejidad de la sociedad actual, la cultura digital y globalización de la cultura, el influjo de los medios de comunicación en la forma de comprender la realidad, todo un conjunto de desafíos ante una fe que se transmite de manera interpersonal.

Elaborar un documento como el DC no debe ser una tarea fácil, y hay que agradecer el esfuerzo de la Iglesia por actualizar el DGC a las nuevas circunstancias. Aun así el anterior DCG sigue siendo un documento a guardar y utilizar porque su síntesis de la evangelización y de la iniciación cristiana sigue siendo óptima. Creo que son dos documentos a mantener unidos.

\section{Qué dice el DC sobre la pastoral juvenil}

Bajo el nombre de PJ se engloban muchas tareas desarrolladas por la comunidad cristiana. Por un lado la PJ ejerce una función de primer anuncio, de evangelización de los alejados de la fe y de ayuda al crecimiento humano y espiritual de los jóvenes. En este sentido se sitúa en la frontera queriendo anunciar a Jesús de Nazaret entre aquellos que bien le conocen algo, poco o nada. A la vez que ofrece procesos de primer anuncio (DC 66-89), también propone una ca-

19 También se detallan las dimensiones del "saber" (DC 143-147) y del "saber hacer" (DC 148-150).

20 Este es un aspecto muy poco desarrollado en el DC. 
tequesis kerygmática, procesos catequéticos de iniciación cristiana (DC 69-71) y de vinculación con la comunidad eclesial ${ }^{21}$ (DC 88-89). Por ello la lectura de los puntos del DC 11-109 pueden otorgar un buen marco para seguir situando la labor de la PJ.

En este apartado vamos a señalar aquellos aspectos en los que el DC hace referencia a la PJ. Lo haremos en tres secciones. Primero señalando los puntos específicos dedicados a la PJ, una novedad respecto al anterior DGC, que apenas desarrollaba esta realidad. Segundo aquellos puntos del DC, que no estando directamente relacionados con la PJ resultan muy inspiradores para ella y tercero, aquellos números relacionados con la integración de la PJ en el dinamismo evangelizador.

\subsection{Puntos específicos sobre la pastoral juvenil DC 244-256}

Lo primero a destacar es que el DC ha desarrollado unos números específicos relacionados con la PJ 22 (DC 244-256) y se amplia lo expuesto en DGC 181-185 sobre la catequesis de los jóvenes. De hecho el término PJ no aparecía en el anterior DGC. Sin embargo esta terminología sobre la PJ sí aparece en EG (105-109) y en ChV. El DC señala la importancia de la PJ como oportunidad para el rejuvenecimiento de la Iglesia (DC 244). El número DC 245 es sumamente importante, porque sitúa la catequesis de los jóvenes dentro del contexto más amplio de la PJ; distingue entre preadolescentes, adolescentes, jóvenes y jóvenes adultos; invita a profundizar en el estudio de la realidad juvenil, así como traducir a su lenguaje el mensaje de Jesús. En este número se pone de manifiesto el influjo de las redes sociales en la configuración de una cosmovisión que afecta a los jóvenes. Toda una declaración de principios ${ }^{23}$.

21 La Pastoral de las instituciones educativas (ChV 221-223 y DC 309-318), en el ámbito de un colegio religioso, se mueve también entre el primer anuncio, la mistagogía, la catequesis y la evangelización como itinerario completo, con la celebración de sacramentos, formación de comunidades juveniles y adultas.

22 DCG (1971) 82-91; EN 72; CT 38-42. DGC 181-185.

23 DC 245: "Las nuevas generaciones están, en general, fuertemente marcadas por las redes sociales y el llamado mundo virtual. Eso ofrece oportunidades que no tenían las generaciones anteriores, pero al mismo tiempo presenta sus riesgos. Es pues de gran importancia considerar cómo la experiencia de las relaciones 
A continuación, se dedican unos números a desarrollar diferentes intuiciones y acentos sobre la realidad de la catequesis con preadolescentes $^{24}$ (DC 246-247), adolescentes (248-249) y jóvenes (250-256). La descripción de la etapa de la preadolescencia es muy adecuada (DC 246), y se señala la importancia de la reelaboración de la imagen de Dios en la preadolescencia (DC 247), un desafío sin duda en la PJ ${ }^{25}$. Se subraya la importancia de las relaciones grupales, la experiencia y el papel del catequista (DC 247).

El DC es consciente del alargamiento de la etapa de la adolescencia en su descripción de la misma (DC 248). Este número 248 plantea un profundo desafio a la catequesis: "desarrollar el espacio interior para captar y acoger sin juicio y con sincera pasión educativa esa búsqueda de libertad de los adolescentes, empezando por conducirla hacia un proyecto de vida abierto y audaz". Su diagnóstico de parte del núcleo del problema de la transmisión de la fe en esta etapa es óptimo:

"Uno de los desafíos de la catequesis es precisamente el poco testimonio de la fe vivida dentro de las familias y de los ámbitos de socialización en los que viven. el alejamiento de los adolescentes de la Iglesia, no depende tanto de la calidad de lo propuesto en los años de la infancia -aunque ello es importante también- sino de una propuesta alegre y significativa para la edad juvenil. Es importante que la catequesis se realice dentro de la pastoral juvenil con una fuerte connotación educativa y vocacional, en el contexto de la comunidad cristiana y en los entornos de la vida de los adolescentes." (DC 249).

A continuación, el DC dedica 7 números a la realidad de los jóvenes (DC 250-256). Comienza este bloque señalando las situaciones sociales en las que se encuentran los jóvenes (DC 250). Al detallar la situación religiosa de los jóvenes señala su pluralidad, y su análisis resulta excelente: "Entre las causas, es necesario considerar la falta

tecnológicas, construye la concepción del mundo, la realidad y las relaciones interpersonales".

24 La preadolescencia era una etapa ignorada en DGC 181.

25 Aquí nos encontramos con uno de los desafíos en la PJ y en la Pastoral escolar. Un riesgo en esta etapa de la PJ es que el juego, elemento indispensable, opaque una formación que ayude al preadolescente a formar una nueva imagen de Dios. 
de testimonio, credibilidad, la ausencia de apoyo espiritual y moral por parte de la familia, o una catequesis débil, o una comunidad cristiana poco significativa" (DC 25026).

El DC 252 ofrece un horizonte para la PJ: "será, en primer lugar, una animación de carácter humanizador y misionero capaz de reconocer en la experiencia humana los signos del amor y de la llamada de Dios". El DC anima a buscar nuevos estilos y estrategias con flexibilidad y siguiendo a ChV 204, impulsa a proponer experiencias de encuentro entre ellos donde compartir la fe. Todo proyecto formativo estará centrado en dos grandes ejes: "uno es la profundización del kerygma, la experiencia fundante del encuentro con Dios a través de Cristo muerto y resucitado. El otro es el crecimiento en el amor fraterno, en la vida comunitaria, en el servicio" (ChV 213; DC 253).

Este número DC 253 afirma: "se requieren itinerarios formativos elaborados en referencia a las experiencias de la vida." Así mismo señala cómo "el camino a la fe de los jóvenes está mediado por la pertenencia a una asociación o movimiento eclesial. De hecho, la dinámica del grupo, permite que la catequesis permanezca íntimamente conectada con la experiencia concreta ${ }^{27}$. Finalmente se valora la catequesis ocasional realizada en la escuela ${ }^{28}$ y las universidades (DC 254), así como la aportación de los jóvenes a la catequesis ${ }^{29}$ (DC 255).

\subsection{Puntos estimulantes para la pastoral juvenil}

El DC no solo ofrece unas indicaciones muy valiosas para la pastoral de juventud, sino que ofrece perspectivas audaces que son verdaderos acentos para la PJ.

26 A esto añadiría el influjo poderoso de una cosmovisión que condiciona la posibilidad de la fe.

27 La realidad de las asociaciones, movimientos y grupos de fieles se desarrolla en DC 304-308.

28 Sobre la escuela católica y la enseñanza de la religión en la escuela Cf.. DC 309318 , donde la escuela es contemplada como una comunidad de fe (DC 310), sujeto de fe (DC 311).

29 El número 256 reflexiona sobre las dificultades de los jóvenes para realizar una transición a la vida adulta. 


\subsubsection{Cuatro horizontes para la pastoral juvenil}

El DGC de 1991 contiene cuatro afirmaciones centrales para la catequesis y para la PJ, muchas veces no tenidas en cuenta y no llevadas hasta sus últimas consecuencias. El DC continua estos acentos:

Primero, el objetivo de la catequesis y del proceso evangelizador es el encuentro con Cristo (DC 75). El DC sigue la formulación de $\mathrm{CT}^{30} \mathrm{y}$ del DGC. "En el centro de todo proceso de catequesis está el encuentro vivo con Cristo. El fin definitivo de la catequesis es poner a uno no sólo en contacto sino en comunión, en intimidad con Jesucristo" (CT 5 y DC 75), lo cual debe desarrollarse también con acompañamiento ${ }^{31}$. Por tanto las tareas de la catequesis ${ }^{32}$ (79-89) están orientadas a ese fin. El DGC y el DC dejan claro que este encuentro profundo se nos va regalando en diferentes etapas del proceso pero tiene como horizonte el encuentro con Cristo en un momento de adultez, porque la fe es diálogo, encuentro entre dos libertades.

Segundo el catecumenado ha de ser fuente de inspiración para la catequesis (DC 61-65), lo cual significa asumir su estilo y dinamismo formativo (DC 64). Esto implica etapas, ritos, etc ${ }^{33}$. Esto sí está bastante asumido por la PJ, aunque no sabemos si es de manera consciente. Se abren excelentes posibilidades al catecumenado en este DC que nos podemos desarrollar aquí.

Tercero la catequesis de adultos es la forma principal de la catequesis ${ }^{34}$ (DC 77). Esto debe ser un horizonte para la PJ y la catequesis en general,

30 Objetivo de la catequesis. la catequesis "persigue el doble objetivo de hacer madurar la fe inicial y de educar al verdadero discípulo por medio de un conocimiento más profundo y sistemático de la persona y del mensaje de Nuestro Señor Jesucristo" CT 19. "La comunión con Jesucristo, muerto y resucitado, vivo y siempre presente, es el fin último de toda acción eclesial, y también de la catequesis". DC 426.

31 DC 3 "Finalidad del proceso: la unión íntima con Cristo, debe realizarse con un proceso de acompañamiento".

32 Llevar al conocimiento de la fe; Iniciar en la celebración del Misterio; Formar en la vida en Cristo; Enseñar a orar; Introducir a la vida comunitaria.

33 El RICA es un documento que necesita ser actualizado. No responde al hemisferio Sur de este planeta y fue pensado para un contexto de misión.

34 Catequesis de adultos en (DC 257-265). 
porque la realidad de la catequesis es que está centrada en los niños y en los sacramentos ${ }^{35}$, que es mucho más fácil que trabajar con las familias, con los adolescentes o con los adultos, por no hablar del primer anuncio y de acercarse a los alejados de la fe. Sin embargo en el horizonte de la actividad catequética debe estar el adulto, porque:

La catequesis de adultos, al estar dirigida a personas capaces de una adhesión plenamente responsable, debe ser considerada como la forma principal de catequesis, a la que todas las demás, siempre ciertamente necesarias, de alguna manera se ordenan (DC 77).

Si la catequesis de adultos es la forma principal de la catequesis, entonces la PJ habrá de cotejar sus características, criterios y formas con las de la catequesis de adultos y el catecumenado, no para imitar, pero sí para enriquecerse.

Cuarto, la comunidad cristiana es el origen, el lugar y la meta de la catequesis" (DC 133 = DGC 254), no obra de francotiradores ${ }^{36}$. Este aspecto está desarrollado en el Capítulo IX "La comunidad cristiana sujeto de la Catequesis $^{37 "}$ (DC 283-318).

\subsubsection{La catequesis familiar}

Hemos señalado anteriormente la acertado del diagnóstico de la situación de dificultad actual en la transmisión de la fe según el

35 Esto no significa abandonar la catequesis de los niños y la catequesis familiar. Es más, hemos de redoblar esfuerzo en la catequesis familiar, y en todas las etapas del proceso: "En este camino, en el que interviene de manera decisiva el sujeto mismo con su personalidad, la capacidad de acoger el Evangelio es proporcional a la situación existencial y a la etapa de crecimiento de la persona" (DC 77), pero con el horizonte de posibilitar un encuentro en la madurez entre la persona y Cristo.

36 DC 11l. Toda la comunidad cristiana es responsable del ministerio de la catequesis. El catequista pertenece a una comunidad cristiana y es una expresión de la misma. Su servicio es vivido dentro de una comunidad. DC 164. La comunidad cristiana es en sí misma catequesis viviente.

37 donde se detalla el papel de las parroquias (DC 298-304), de las asociaciones y movimientos (DC 304-308), la escuela católica (DC 309-318), la cual es reconocida como sujeto eclesial (DC 311), "llamada a penetrar en el ámbito de la cultura y de relacionarse con los demás saberes" y a la que en el contexto "representa para los estudiantes la única ocasión de contacto con el mensaje de la fe" (DC 313) 
DC 249, donde entre otros factores se señalaba que: "uno de los desafíos de la catequesis es precisamente el poco testimonio de la fe vivida dentro de las familias". El DC no se ha quedado en un mero diagnóstico acertado sino que dedica 21 puntos a la familia y la sitúa en el primer punto en el capítulo VII en el "Desarrollo de la catequesis en la vida de las personas ${ }^{38}$ ". El DC recalca cómo la familia es sujeto de la catequesis (DC 231) y cómo los padres han de ser sujetos activos en la catequesis lo cual requiere ${ }^{39}$ :

"un esfuerzo evangelizador y catequístico dirigido a la familia", que la oriente en este sentido (AL 200.) El mayor desafío en este caso es que las parejas, padres y madres, sujetos activos de la catequesis, superen la mentalidad tan común de delegar a otros, según la cual la fe está reservada a los llamados especialistas de la educación religiosa. (DC 124).

Es de destacar el acercamiento positivo a las nuevas realidades familiares (DC 233-235), a la vez que se destaca cómo la familia es "un anuncio de fe en cuanto lugar natural en el cual la fe puede vivirse de manera sencilla y espontánea "(DC 227). Se subraya cómo "la comunidad y la familia son, la una para la otra, una referencia constante y mutua" (DC 229) y cómo "la catequesis con las familias tiene su punto central en el kerygma” (DC 230).

Son muy acertados tanto el diagnóstico como los acentos señalados a la catequesis familiar. Los estudios socio religiosos señalan este diagnóstico. Sin transmisión de la fe en la familia es muy difícil que se pueda desarrollar la fe en el adolescente y en el joven. La familia sigue

38 Esta realidad familiar estaba bastante ausente en el DGC. A su favor se ha de señalar que la catequesis de adultos ocupaba el primer punto en el desarrollo de la catequesis por edades, lo cual realzaba su protagonismo. Esto se ha perdido en este DC, aunque se sigue señalando su papel central (DC 77).

39 La relación entre catequesis y familia se desarrolla en tres apartados: La catequesis en la familia (DC 227-228); la catequesis con la familia (DC 229-239); la catequesis de la familia (DC 231). El protagonismo de la familia y la catequesis familiar aparece de manera tímida en el DGC aparece de manera tímida. "La catequesis familiar es, en cierto modo, insustituible, sobre todo por el ambiente positivo y acogedor, por el atrayente ejemplo de los adultos, por la primera y explícita sensibilización de la fe y por la práctica de la misma" (DGC 178).

40 La vida matrimonial y familiar, vivida según el plan de Dios, es ya un Evangelio en sí mismo (DC 228). 
siendo condición necesaria, aunque no suficiente para la transmisión de la fe $\mathrm{f}^{41}$. Aquí se abren posibilidades a la PJ, cómo colaborar más con las familias, cómo incluir a las familias en la PJ, cómo conectar la PJ con la familia, la escuela, la parroquia y la catequesis ${ }^{42}$.

\subsubsection{Desafíos culturales para la pastoral de juventud}

El capítulo X dedicado a los desafíos culturales contemporáneos es realmente estimulante y acertado. Todos los temas desarrollados aquí son interpelantes para la PJ. Comienza este capítulo de obligada lectura situando la catequesis en la situación social actual de pluralismo y complejidad ${ }^{43}$ (DC 320-342), analiza las peculiaridades del contexto urbano y rural (DC 326-330), así como a los desafíos de la piedad popular (DC 336-342) y del pluralismo religioso de nuestras sociedades ${ }^{44}$ (DC 343-353).

El apartado realmente significativo es el tercero, donde se desarrollan las relaciones entre Catequesis y ciencia (DC 354-358), Catequesis y cultura digital (DC 359-372), Catequesis y Bioética (DC 373-378), Catequesis y compromiso ecológico (DC 381-384) y Catequesis y compromiso por los pobres (DC 381-391). Todos ellos son aspectos actuales e importantes para la PJ.

El DC aborda el problema de la relación ciencia y fe ${ }^{45} \mathrm{y}$ ofrece pistas para cómo abordarlo en la catequesis y señala que "las perso-

41 Este aspecto lo hemos desarrollado en varios estudios.

42 A. Delgado Gómez, «La colaboración sinérgica entre la familia, la parroquia y la escuela católica», Sinite 56169 (2015) 273-302.

43 Es necesario tener en cuenta la complejidad del mundo contemporáneo y la conexión íntima existente entre la cultura, la política, la economía, el trabajo, el medio ambiente, la calidad de vida, la pobreza, los conflictos sociales, las guerras. LS 17-52 y DC 173.

44 Algunas de estas dimensiones ya aparecían en el DGC.

45 El desafío que supone la cosmovisión simplificada que proponen los medios de comunicación en los que se simplifican los datos científicos es un desafío para la PJ, dado que la configuración de esa cosmovisión ecléctica en los jóvenes impide muchas veces el anuncio del evangelio. La Iglesia tiene el gran desafío de presentar su mensaje ofreciendo una cosmovisión que permita integrar el mensaje de Jesucristo con una cosmovisión compatible con la ciencia. La catequesis y la enseñanza de la religión deben afrontar la presentación de la ciencia, la filosofía y la religión como complementarias. 
nas, fascinadas por una mentalidad científica, se preguntan cómo la ciencia puede conjugarse con los datos de la fe" (CE 354). Este es un desafío sin igual para la PJ, dado que muchos jóvenes interpretan que ciencia y religión son incompatibles. Por tanto la relación ciencia y religión debe ser objeto de la catequesis y del primer anuncio. Al tratarlos, "la catequesis entonces sabrá plantear preguntas y sugerir temas de particular importancia, como la complejidad del universo, lo creado como señal del Creador, el origen y fin de la persona y del cosmos" (CE 357). La Iglesia y la PJ se enfrentan a un profundo desafio: "facilitar una verdadera y apropiada inculturación de la fe en el mundo científico" (DC 358).

El tema de la cultura digital es abordado profundamente en el DC y es de agradecer, señalando sus posibilidades y riesgos (DC 361-364) de una manera equilibrada. Al analizar la cultura digital el DC subraya el profundo influjo de ésta (DC 359) y también señala cómo esta cultura digital se presenta a menudo como un fenómeno religioso (DC 365367). En el DC 369, se da en el clavo de la problemática de la transmisión de la fe: "Cada vez se reconoce más que los llamados "social media”, y especialmente los digitales, son ya los principales agentes de socialización, llegando casi a remplazar a los tradicionales como la familia, la Iglesia, la escuela". Especialmente por las horas diarias que se pasan los jóvenes consumiendo estos contenidos digitales frente a las escasas ocasiones que se les ofrecen de silencio, interioridad, catequesis, etc. Anteriormente ha tratado el tema de los medios comunicación (DC 45, 47), un aspecto muy importante para la PJ:

"vivimos en una sociedad de la información que nos satura indiscri-
minadamente de datos, todos en el mismo nivel, y termina llevándo-
nos a una tremenda superficialidad a la hora de plantear las cuestio-
nes morales. Por consiguiente, se vuelve necesaria una educación que
enseñe a pensar críticamente y que ofrezca un camino de madura-
ción en valores". (DC 323). Aquí está planteado uno de los grandes desafíos de la PJ. Este es un tema de primera magnitud como ya hemos señalado anteriormente. Como herramienta catequética, el número DC 371 señala que nuestra pastoral ha de ofrecer experiencias de fe, dado que "la experiencia transforma y ofrece claves interpretativas de la vida”, un tema 
ya desarrollado en profundidad como una de las herramientas de la catequesis (DC 197-200).

También aborda el DC el tema de la moral. Los medios de comunicación bombardean constantemente a los jóvenes con una moral basada en el único valor de la libertad absoluta del yo, raíz de muchos conflictos con la visión moral de la Iglesia. El DC aborda estos temas de manera notable dando referencias acertadas (DC 378). En consonancia con lo anteriormente señalado se ha de dialogar con os jóvenes que "no todo lo que es técnicamente posible es moralmente admisible" (DC 374). En el punto DC 377 se aborda el tema de la ideología de género de manera muy acertada.

La ecología es un valor en nuestra sociedad (DC 382) que toca claramente la sensibilidad de los jóvenes. Esta defensa de la naturaleza entendida como creación de Dios ha sido defendida por el papa en su exhortación Laudato Si, donde ha invitado a una conversión ecológica profunda (DC 381) y por tanto "la cuestión ecológica es parte integrante de la vida cristiana" (DC 384).

\subsubsection{Aspectos catequéticos y pastorales que afectan a la Pasto- ral de juventud}

EL DC también aborda múltiples aspectos relacionados con la catequesis y la pastoral que afectan a la PJ. Uno de los aspectos ineludibles también en la PJ es el tema de la "Metodología de la catequesis" (DC 194-223), donde se desarrolla el tema del lenguaje $^{46}$ (DC 204-217), especialmente el lenguaje digital (DC 213-217) y la importancia del grupo en el proceso catequístico (DC 218-220).

Se señala que "la catequesis no sigue un método único, está abierta a valorar diferentes métodos, confrontándose con la pedagogía” (DC 195). Existen "caminos metodológicos más centrados en los hechos de la vida o más orientados al mensaje de la fe. Eso depende de las situaciones concretas de los sujetos de la catequesis. En uno y otro

46 Se señala el riesgo de que determinadas presentaciones de la fe con un lenguaje ortodoxo no transmiten el contenido del evangelio (DC 167). 
caso, es importante un principio de correlación que ponga en relación ambos aspectos47" (DC 196). Lo que sí deja claro es que "la experiencia humana es parte constitutiva de la catequesis. Es el espacio en el que Dios habla". (DC 197). La labor del catequista con su testimonio y con la ayuda de la Pablara ha de ayudar a "interpretar los hechos de la vida de una manera creyente" DC 121). Se nos recuerda el principio "evangelizar educando y educar evangelizando" recuerda, entre otras cosas, que la obra del catequista consiste en encontrar y mostrar los signos de la acción de Dios ya presentes en la vida de las personas y acompañándolas, proponer el Evangelio como la fuerza transformadora de toda la existencia, a la cual dará pleno sentido (DC 179).

El DC tiene una visión de conjunto del proceso evangelizador (DC 31-37) así como una visión actualizada de lo que significa la evangelización en el mundo contemporáneo (DC 38-549), recordando que estamos en una etapa de nueva evangelización (DC 39) y de salida misionera (DC 49-50), que requiere de una conversión pastoral (DC 40) y cómo la catequesis está al servicio de la nueva evangelización (DC 48) y que ha de desarrollarse de una manera dialogal (DC 54).

La conexión de la PJ, la pastoral escolar y universitaria con la catequesis se explicita en DC 420-421, destacando que la acción pastoral de la Iglesia es más amplia que la catequesis ${ }^{48}$ (DC 420) y se impulsa la formación de una "comisión de iniciación a la vida cristiana, en la que confluyan la pastoral del primer anuncio y la catequesis, la pastoral litúrgica y la Cáritas, las asociaciones y los movimientos laicales" (DC 421).

47 "El misterio de la encarnación inspira la pedagogía de la catequesis. Esto también tiene implicaciones para la metodología de la catequesis, que debe referirse a la Palabra de Dios y al mismo tiempo asumir los casos auténticos de la experiencia humana" (DC 194).

48 DC 420. Es importante que la catequesis se articule con las otras dimensiones de la pastoral de la Iglesia particular... La catequesis tiene una estrecha relación con la pastoral familiar, juvenil y vocacional, así como con la pastoral escolar y universitaria. Aunque si la acción pastoral de la Iglesia es más amplia que la catequesis, ésta -por razón de su función iniciática- la vivifica y la hace fecunda. El énfasis kerygmático y misionero de la catequesis hoy favorece la conversión pastoral y, por lo tanto, la transformación misionera de la Iglesia. DC 420. 
Las reflexiones sobre el Proyecto diocesano de catequesis (DC 423) son muy abiertas, reconociendo la necesidad de una "estructuración diversificada de la de la propuesta formativa”, así como la necesidad del acompañamiento personal.

\section{Conclusión}

Hemos intentado presentar algunos aspectos del DC relacionados con la PJ, con el único objetivo de animar a la lectura y reflexión del DC, un documento que se presenta con los pies en la tierra, capaz de hacer un diagnóstico real de muchos de las oportunidades y problemas en el proceso de la transmisión de la fe, y que no se queda centrado en la catequesis, sino que es un verdadero pequeño manual de evangelización, integrando y estimulando a salir al encuentro de la personas, al primer anuncio, a la catequesis kerygmática, a la iniciación cristiana y a la formación permanente de los adultos en la fe.

El diagnóstico de los desafíos a los que nos enfrentamos en la transmisión de la fe, así como la propuesta sistemática del objetivo y de las tareas de la catequesis hacen de este documento un "must read" por parte de los agentes pastorales dedicados a la catequesis con los jóvenes así como por parte de los responsables de pastoral de juventud de colegios, universidades, congregaciones y movimientos. Todos ellos disponen de un documento muy sugerente con el que poder testear la calidad y las apuestas de sus procesos pastorales. La intuición del papa Francisco de poner en primer término la catequesis kerygmática es una propuesta muy sugerente y que ha de ser tomada en cuenta por los educadores en la fe. Asimismo este documento va por delante de muchos proyectos pastorales en su análisis y en las soluciones que ofrece a temas centrales en la vida de los jóvenes como la ecología, la moral, las diferentes situaciones familiares, la cultura digital, etc., temas que podrían ser todos ellos objeto de un diálogo para mejorar nuestros planes pastorales.

El DC es un texto limitado y que contiene puntos débiles, como no puede ser de otra manera. Creo que no elimina y deja fuera de circulación al anterior DGC que sigue siendo una obra de referencia. Teniendo claro que el objetivo del DC no es ser un plan de pastoral 
de juventud, ofrece sin embargo criterios y pistas para su desarro1lo. Uno de los temas que queda cojo en este DC y que se habrá de abordar es el tema de la inculturación de la liturgia para adaptarla al mundo joven, algo deseado por los peritos después del concilio Vaticano II, pero que quedó parado, incluso con una parte del misal destinado a las celebraciones con los jóvenes ya casi terminado ${ }^{49}$.

Este texto no es un documento más publicado por la Iglesia sino una posible brújula que puede alumbrar el futuro de nuestros planes pastorales dedicados a la evangelización de los jóvenes. A su vez es un buen test sobre la vigencia y actualidad de nuestros planes, una guía con la que cotejar lo que desarrollamos, para no seguir haciendo más de lo mismo, como la catequesis centrada en los niños, y tantas actividades pastorales que son las mismas de hace cuarenta años, cuando en los últimos años se ha producido un cambio cultural enorme, como bien señala el DC, por ejemplo cuando aborda el desafío de la cultura digital, la ecología, la moral, etc. Mi intención con este articulo ha sido animar a la lectura del DC, convencido de que tiene mucho que aportar a una buena programación pastoral con los jóvenes.

49 A. Bugnini, La reforma de la liturgia 1948-1975, BAC, Madrid 1999, 156; 376-377. J. M. Lera, La Iglesia hace la Eucaristía y la Eucaristía hace la Iglesia, Mensajero, Bilbao 2019, 291-354. 